\title{
Impact Analysis of Reservoir Water-level Fluctuation on Building Foundations on Bank Slopes
}

\author{
Wu Liming ${ }^{1}$, Yang Bo ${ }^{2, *}$, Wang Zijian², Zhang Jianing ${ }^{2}$ and Yuan Shifeng ${ }^{3}$ \\ ${ }^{1}$ School of Urban Construction Engineering, Chongqing Technology and Business Institute, Chongqing, 401520, China \\ ${ }^{2}$ School of Civil Engineering and Architecture, Chongqing University of Science and Technology, Chongqing 401331, China \\ ${ }^{3}$ A\&T engineering P.C., New York, NY11358, United States
}

Received 27 July 2020; Accepted 4 December 2020

\begin{abstract}
Reservoir water-level fluctuation can alter the bearing capacity and stability of foundations on bank slopes by changing local seepage and stress fields, thus inducing displacement deformation of building foundations. A 2D saturatedunsaturated seepage model was constructed with ABAQUS for simulation calculation of the bank slope and buildings in the Shanganping Village, Wushan Section of the Three Gorges Reservoir Region, China. This task was conducted to investigate the influencing law of reservoir water-level fluctuation on building foundations on bank slopes and assure their safety. Subsequently, a comparative analysis about the variation laws of underground water and stresses and displacement of building foundations on bank slopes when the reservoir water-level fluctuation rate varies was carried out. Results show that the height ratio of the trailing saturate line at the side slope is 1.19 when the rate of the reservoir water-level rise is 1 and $3 \mathrm{~m} / \mathrm{d}$. Such finding indicates that the hysteresis effect of saturation line is highly obvious when the rate of the reservoir water-level rise is high. The maximum difference of effective stresses at the bottom of the pile foundation is $5 \mathrm{KN}$ when a reservoir water-level fluctuation exists. This finding reveals that the reservoir water-level fluctuation will induce great changes to the stress state of building foundations. The maximum displacement of pile foundation is positively related with the rate of reservoir water-level fluctuation. Such a notion reflects that the rate of reservoir water-level fluctuation is a key influencing factor of deformation behaviors of bank slopes and buildings. During a reservoir water-level fluctuation, the settlement value is negatively correlated with the distance between the pile foundation and the frontal edge of the side slope. The error of settlement between the finite element simulation and the theoretical calculation results is lower than $10 \%$, which verifies the accuracy of the numerical simulation in this study. The research conclusions can provide some references to the safety evaluation of existing buildings and design of new buildings on bank slopes.
\end{abstract}

Keywords: buildings on reservoir banks, seepage field analysis, stress field analysis, saturated-unsaturated seepage

\section{Introduction}

Many reservoir dams have been built on rivers in countries in the world during the past decades to fully use the water resources and solve the energy shortage problems. Many cities are situated near the mountain and by the river on two banks of rivers. These cities possess a great deal of buildings on bank slopes. The quantity of new buildings on the bank slopes in the Three Gorges Reservoir Region (e.g., Wu shan and Wan zhou) achieves an accelerated growth trend with economic and social development and insufficient construction land. Nevertheless, the construction of reservoirs altered the original hydrogeological conditions at two banks of rivers and thereby affected the safety of buildings on the bank slopes. An increasing number of reservoirs finished the initial trial operation and began to be utilized in commercial operation in recent years. The amplitude and frequency of reservoir water-level fluctuation gradually increase, which further intensifies the impacts on buildings on bank slopes. Therefore, the influencing laws of reservoir water-level fluctuation on buildings on bank slopes must be explored to formulate the corresponding measures

*E-mail address: chongqingyangbo@163.com

ISSN: 1791-2377 @ 2020 School of Science, IHU. All rights reserved. doi:10.25103/jestr.136.15 for structural improvement.

Differential settlement develops on the bank slopes due to reservoir water-level fluctuation. Such a phenomenon caused structural failures of buildings on the bank slopes. This event occurs because rock soil is the main component of side slopes. Rock soil is a type of media with continuous pores, and its physical and mechanical properties are influenced by water to a large extent. The underground water level and soil moisture content in side slopes change with reservoir water-level fluctuation, thus leading to variations of the bearing capacity and stability of the foundation. In traditional studies, most scholars believe that reservoir water-level fluctuation may alter the soil moisture content to further cause changes in the mechanical properties, such as elasticity modulus, Poisson's ratio, internal friction angle, and cohesion, thereby influencing the deformation and stability of side slopes [1-2]. Some scholars believe that the parameter deterioration of rock soil caused by reservoir water-level fluctuation is a primary influencing factor of slope stability. The rock soil mass undergoes the water absorption-dehydration cycle with reservoir water-level fluctuation, during which the mechanical parameters deteriorate [3]. Certain parameters, such as elasticity modulus and Poisson's ratio, are related with the bearing capacity of the foundations. When the reservoir water level 
fluctuates, settlement of buildings might change with the bearing capacity of the foundations [4]. Traditional studies focus on the influences of reservoir water-level fluctuation on the rock soil parameters of bank slope. Seepage force and matrix suction of rock soil mass on bank slopes of reservoirs may change with reservoir water-level fluctuation, except for the physical and mechanical parameters. This phenomenon is one of main influencing factors of slope stability. The bank slope is next to the reservoir, and the underground water level often significantly changes at a high frequency as a response to reservoir water-level fluctuation. The saturation state of soil mass might frequently change. Due to soil absorption or dehydration, the state of the soil will change between saturated and unsaturated. This phenomenon not only can directly alter the matric suction of soil mass but also may generate seepage forces to change the original stress-strain relationship of soil mass. Accordingly, the bank slope develops displacement deformation, which causes differential settlement failure of upper buildings. Therefore, traditional studies have the following disadvantages: the settlement and deformation of foundations on bank slopes are considered the influences of the parameters of soil mass only; however, but they ignore the influences of seepage effect and matric suction. Finite element software ABAQUS not only owns a strong seepage analytical module but also simulate variations of seepage effect and matric suction and analyze the structural damages. In this study, ABAQUS was chosen for analysis.

In this study, an overall model of bank slope and buildings on the slope in Shan gan ping Village, Wu shan Section of the Three Gorges Reservoir Region, China was constructed on the basis of 2D saturated-unsaturated seepage theory for numerical simulation. The results were compared and analyzed to obtain the variation laws of stress and displacement of the side slope and building foundations under different rates of reservoir water-level fluctuation. The influencing laws of the reservoir water on buildings on the bank slope were discussed.

\section{State of the art}

Studies concerning the influences of reservoir water-level fluctuation on buildings of bank slopes have been conducted. This issue is an increasingly outstanding problem in recent years. To date, scholars worldwide have carried out a large number of studies about the influences of reservoir waterlevel fluctuation on buildings of bank slopes through field monitoring and experimental method. The studies have concluded that some fruits are applicable to the structural design of buildings on bank slopes. However, these studies mainly focus on apparent phenomena, such as searching influencing laws and changes of the bearing capacity of foundation. Nevertheless, no deep study on the influencing and action mechanisms has been reported yet. For example, Huang [5] explored brickwork and cast-in-situ houses on reservoir banks through field observation and data monitoring. Results demonstrate that the underground water level significantly fluctuates when a heavy rainfall or flood discharge occurs in the reservoir region, thus making differential settlement of house foundation close to the reservoir more obvious. Li [6] carried out a site systematic test on the bearing capacity, side friction, and end resistance of the foundation piles before and after immersion in water at the bank slope of the Three Gorges Reservoir. He concluded that soil mass softening by water can influence bearing capacity and settlement deformation of pile foundation of buildings on side slopes. None of these research results have explored the essence of the influences of reservoir water on buildings, which are on bank slopes. Accordingly, specific measures to improve the structures are not formulated. The essence of impact must be explored to prevent structural failures of buildings on the bank slope.

First, reservoir water-level fluctuation changes the stability of side slope, which further influences buildings above it. Accordingly, slope stability is one of the fundamental causes for displacement deformation of buildings on bank slope. Laiser (1883), a British scholar, is the first to study slope stability. He mentioned landslide for the first time in the book of Principles of Geology and believed that slope instability is the direct consequence of an underground water effect. This notion lays theoretical foundation to study slope stability. Vipin [7] studied the causes of landslide in Urni by combining field monitoring and numerical simulation and found planar failure and wedge-shaped failure of joint rock masses in the side slope when extreme rainfall occurs. However, he did not analyze the influences of reservoir water-level rise in detail (the slope is next to the reservoir). Shruti [8] carried out a statistical and regression analysis on the precipitation and landslide events in Kerala, India and found a significant relationship between daily precipitation and landslide. However, the landslide mechanism caused by rainfall has not been explored. David [9] carried out a systematic study on the evolutionary law of fault in a bank slope under the impact effects of river water through field investigation and simulation calculation; however, he did not explore the deformation law of rock mass in a bank slope. Joynal [10] studied the characteristics, causes, and consequences of mountain landslides in Rangamati, Bangladesh. The author found that landslide scale and annual precipitation were significantly correlated with altitude. Nevertheless, the direct causes of landslides have not been studied. Binh [11] chose some regions that easily cause landslides in Sampitolagal on the north of Himalayas, India as the study area and developed a landslide prediction model on the basis of RFSVM. However, he neither has involved reservoir waterlevel fluctuation nor be suitable to bank slope projects. Vito[12] proposed a new method to determine the threshold of landslides on the basis of the relationship between the duration of rainfall and the dynamics of a rainfall-induced landslide. Moreover, he compared the research results with 51 examples of landslides and proved that the equation method based on the size and distribution of rain drops is the optimal method to determine the threshold of landslides. However, this equation method is inapplicable to bank slope engineering. In the background of rainfall-induced landslide events in Western Ghats in India, Manoj [13] conducted a numerical simulation by combining the precipitation estimation of Tropical Rainfall Measuring Mission and Global Precipitation Mission and the rainfall data provided by Indian Meteorological Department. He concluded the variation laws of precipitation rate and total precipitation that cause large landslides, but he did not analyze the direct cause of landslides - seepage effect. The above-mentioned studies about the influences of reservoir water-level fluctuation mainly focus on stability changes, failure mode, failure law, and settlement failure of a slope. However, only few studies have discussed the influences of structures near the side slope on reservoir water-level fluctuation.

Given that the influences of reservoir water-level fluctuation on buildings on the side slopes are increasingly 
prominent, relevant studies attract increasing attention from scholars. To date, many scholars worldwide have studied settlement failure of buildings. Raffaele [14] investigated a failure mechanism of the masonry structure when settlement of foundation exists and gained the corresponding local or overall failure mode. Gianmarco [15] proposed a simple constitutive model that used a descriptive masonry wall as an elastoplastic homogeneous anisotropic plate. This constitutive model successfully predicted the failure mechanism and bearing capacity, including the settlement of soil mass and seismic loads of masonry wall under different boundary and loading conditions. Eugeniusz [16] analyzed the influences of foundation settlement on deformation and stress state of the bottom steel plates when the foundation type and settlement varied through numerical simulation. Paolo [17] calculated the collapse mechanism shape, supporting the counterforce and thrust line of masonry arch without horizontal arching settlement by using the virtual work principle. Under the hypothesis of finite displacement, each step of arching settlement was described by an iteration algorithm. The ultimate displacement of masonry arch at complete failure when no horizontal resilience settlement exists was determined through an iterative scheme. Finally, the accuracy of the analytical method was verified through an experiment. Jamie[18] discussed the failure mechanism and failure mode under an asymmetric linear vertical displacement through an experimental study to further understand the influences of differential settlement on the structural response of the arc top of a pointed cylinder. The author also evaluated the suitability of FRP as a reinforcement method to improve the stability of the arc top of the pointed cylinder. Richard[19] studied the failure of floor plates of buildings supported by stone pillars in extreme soft clay under normal uses and identified that the design and construction defect of stone pillars are two main causes. Bayer[20] monitored the deformation of side slope caused by tunnel excavation by using an advanced SAR technology and concluded the influencing law.Casagli[21] plotted and monitored landslides on the basis of radar and optical remote sensing and found that most landslides occurred during rainfall periods. Based on the mosque in Hoca Pasha, Turkey, Dalgic[22] simulated the settlement process of "foundation-mosque" by using the two-stage numerical analysis method. He analyzed the stress and cracks caused by settlement in detail. The simulation results demonstrated that the possibility of settlement occurrence of the mosque decreased with the increase in rigidity ratio between the foundation soil and the upper structure. However, these studies only analyzed the influences of foundation settlement on buildings above the foundation but have not discussed the influences of seepage and underground water-level fluctuation. These research conclusions cannot provide reliable support to formulate reasonable measures to improve building structures under the influences of reservoir water-level fluctuation.

$\mathrm{Lu}[23]$ constructed a flac3D model for the bank slope with a large slip in Miaowei hydropower station and analyzed the influences of reservoir water-level fluctuation and precipitation on the transient water level in the bank slope. Fang[24] analyzed the collaborative effects of reservoir water level and precipitation on the slope stability through finite element software. The result showed that the safety coefficient of the side slope significantly decreased due to the combined influences of the reservoir water-level decrease and precipitation. Guo[25] conducted a hydrological simulation on the basis of PCSIWAPRO and improved the method to calculate the safety coefficient of the soil slope. Liu,[26] chose bridge foundation on a side slope in a reservoir region as the research object and constructed a 2D saturated-unsaturated seepage model. The analytical result indicated that the deformation of the bridge foundation on the reservoir banks was related with reservoir water-level fluctuation and rate of reservoir water-level fluctuation. Nevertheless, the pile-soil contact problem was not processed. This issue was a universal problem in the current associated research fields. The staged separating calculation method is often applied in simulation calculation due to the high complexity and heavy computational workloads of fluid-solid coupling calculation. In this method, the pile-soil interaction is neglected.

These studies have proved that reservoir water-level fluctuation exerts significant influences on the slope stability and deformation of local buildings. However, relevant analytical methods have some defects and neglect the pile soil interaction. In practical engineering, reservoir waterlevel fluctuation may cause deformation of bank slopes, which can further induce deformation of building foundations. Meanwhile, the building foundation has constraint over the side slope and decreases the practical deformation of the side slope. A complicated interaction can be observed between the foundation and the side slope.

A 2D fluid - solid coupling overall model was constructed and studied on the basis of the saturatedunsaturated seepage principle to address the disadvantages of existing studies. The variation laws of stress and displacement of building foundations on the bank slope under a reservoir water-level fluctuation were investigated through comparative analysis of calculation results under various working conditions.

The remainder of this study is organized as follows. Section 3 elaborates the basic theory and finite element model. Section 4 analyzes the calculation results under various working conditions. Section 5 summarizes the conclusions.

\section{Methodology}

\subsection{Basic theory}

\subsubsection{Seepage governing equation}

The seepage laws of the saturated and unsaturated soils are generally believed to be conforming to the Darcy law (Eq. [1]). Specifically, the flow in unit time on the seepage surface (q) is equal to the product of permeability coefficient (k) and hydraulic gradient (i).

$$
q=k \times i
$$

In this study, the functional relationship between permeability coefficient and saturation of soil was controlled by the relation equation proposed by Cho et al. [27]. Such functional relationship is expressed as Eqs. (2) and (3). The relation curve, which is calculated by these equations, is shown in Fig. 1

$$
\mathrm{k}_{\mathrm{w}}=\mathrm{a}_{\mathrm{w}} \mathrm{k}_{\mathrm{ws}} /\left\lfloor\mathrm{a}_{\mathrm{w}}+\left(\mathrm{b}_{\mathrm{w}} \times\left(\mathrm{u}_{\mathrm{a}}-\mathrm{u}_{\mathrm{w}}\right)\right)^{\mathrm{c}_{\mathrm{w}}}\right\rfloor
$$

where $\mathrm{kw}$ is the permeability coefficient of the unsaturated soil mass, and kws is the permeability coefficient of saturated soil mass, which is determined as $5 \mathrm{E}-6 \mathrm{~m} / \mathrm{s}$ in this study. ua and uw are air pressure and 
hydraulic pressure in soils, respectively. aw, bw, and cw are material coefficients, which are 1000, 0.01, and 1.7, respectively.

$\left.\mathrm{S}_{\mathrm{r}}=\mathrm{S}_{\mathrm{i}}+\left(\mathrm{S}_{\mathrm{n}}-\mathrm{S}_{\mathrm{i}}\right) \mathrm{a}_{\mathrm{s}} / \mathrm{a}_{\mathrm{s}}+\left(\mathrm{b}_{\mathrm{s}} \times\left(\mathrm{u}_{\mathrm{a}}-\mathrm{u}_{\mathrm{w}}\right)\right)^{\mathrm{c}_{\mathrm{s}}}\right\rfloor$

where $\mathrm{Sr}$ is the saturation degree; $\mathrm{Si}$ is the residual saturation degree; $\mathrm{Sn}$ is the maximum saturation degree; and as, bs, and cs are the material parameters, which are $1,5 \mathrm{E}-5$, and 3.5 , respectively.

A layer of shrinking film is present on the air - water interface in unsaturated soils. This film bears porous air pressure and its load. The difference between pressure of the shrinking film and porous air pressure is the matric suction. Matric suction is related with the saturation degree of soil mass, and it is controlled by the moisture absorption curve, which is calculated by Eq. (3). The relation curve between matric suction and saturation degree is shown in Fig. 2.

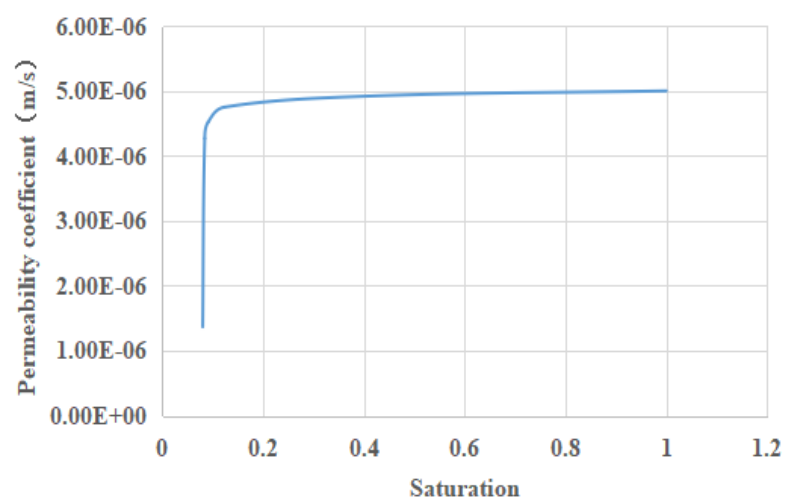

Fig. 1. Relation curve between permeability coefficient and saturation degree

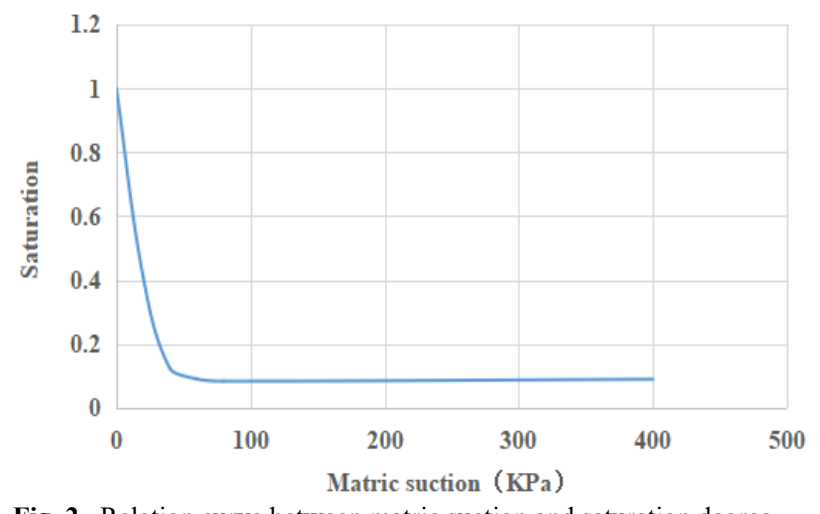

Fig. 2. Relation curve between matric suction and saturation degree

\subsubsection{Constitutive relation of soil mass}

The deformation of saturated soil is determined by the variation of its net stress. The constitutive relation of saturated soil mainly refers to the relation between strain and net stress. The unsaturated soil is influenced by matric suction, except for net stress. Matric suction can bring a large volume of strain to the soil mass. Hence, the constitutive model of unsaturated soil shall simultaneously consider net stress and matric suction. The two independent state variables of matric suction and net stress are generally used to describe stress state of unsaturated soil.
The effective stresses of soil materials in ABAQUS are shown in Eq. (4). In Eq. (4), $x$ is the effective stress parameter, and it can be approximately determined as the saturation degree. ua and uw are air pressure and hydraulic pressure in soil because the pores of the soil are connected to the atmosphere, $\mathrm{Ua}$ is equal to 0 , and ua - uw is the matric suction. The effective stress formula in ABAQUS reflects the influences of pore water. Given that the net stress that is undertaken and transmitted by soil mass is related with strain, the classical Mohr - Coulomb yield criterion is applied for definition (Eq. [5]):

$\delta^{\prime}=\delta-\left(\chi u_{w}+(1-\chi) u_{a}\right)$

$\tau=c+\sigma \tan \varphi$

Substituting Eq.(4) into Eq. (5) yields the following shear strength formula:

$$
\tau=\mathrm{c}+\left(\delta^{\prime}-\mu_{a}\right) \tan \varphi+\left(\mu_{a}-\mu_{w}\right) \chi \tan \varphi
$$

\subsection{Finite element model}

In this study, saturated - unsaturated fluid - solid coupling analysis was performed by using finite element software ABAQUS. First, the steady state of the overall model of the bank slope upper building before fluctuation of the reservoir water level was analyzed. The stresses were extracted, and a stress file was set up. Second, the stress file was inputted into the model as the initial condition. The initial stresses were balanced, and a transient analysis was then performed. The pile - soil interaction adopted the "contact", and the bottom of the pile demonstrated a hard contact. The friction coefficient at the pile side was 0.42 . The overall model is shown in Fig. 3.

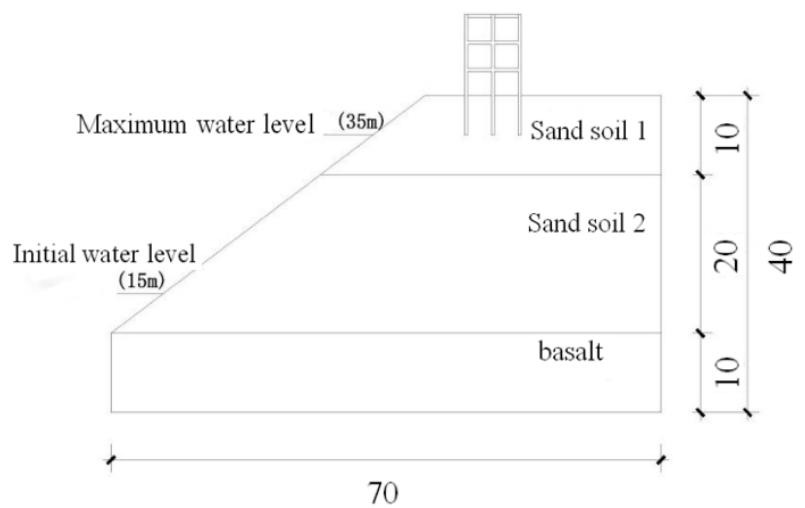

Fig. 3. Overall model (unit: $\mathrm{m}$ )

The upper building was built with $\mathrm{C} 30$ concrete, and the pile foundations were named Pile 1\#, Pile 2\#, and Pile 3\# from the left to the right. The side slope was composed of three layers of rock soil. The upper, middle, and bottom layers were sand soil 1, sand soil 2, and basalt, respectively. The material parameters are listed in Table.1. Three working conditions were calculated, and the results are shown in Table 2 . 
Wu Liming, Yang Bo, Wang Zijian, Zhang Jianing and Yuan Shifeng/

Journal of Engineering Science and Technology Review 13 (6) (2020) 108 - 117

\begin{tabular}{|c|c|c|c|c|c|c|}
\hline Materials & $\begin{array}{l}\text { Volume weight } \\
\left(\mathbf{k N} \cdot \mathrm{m}^{-3}\right)\end{array}$ & $\begin{array}{c}\text { Effective angle of } \\
\text { internal friction } \\
\Phi^{\prime} /{ }^{\circ}\end{array}$ & $\begin{array}{c}\text { Effective elasticity } \\
\text { modulus } \\
\text { E'/MPa }\end{array}$ & $\begin{array}{c}\text { Effective } \\
\text { cohesion } \\
\mathbf{C}^{\prime} / \mathbf{k P a}\end{array}$ & Poisson's ratio & $\begin{array}{c}\text { Saturated } \\
\text { permeability } \\
\text { coefficient } \\
\text { m/h }\end{array}$ \\
\hline Concrete & 20 & - & 36,000 & - & 0.2 & - \\
\hline Sand soil 1 & 12 & 25.3 & 22 & 87 & 0.3 & 0.018 \\
\hline Sand soil 2 & 12 & 25.7 & 24 & 91 & 0.32 & 0.018 \\
\hline Basalt & 20 & 43.1 & $4.62 \mathrm{E} 7$ & 1412 & 0.21 & 0.017 \\
\hline
\end{tabular}

Table 2. Working conditions

\begin{tabular}{c|l}
\hline Working conditions & \multicolumn{1}{c}{ Descriptions } \\
\hline 1 & $\begin{array}{l}\text { The rate of reservoir water-level fluctuation is } 1 \mathrm{~m} / \mathrm{d} \text { : the reservoir water level increases at the rate of } 1 \mathrm{~m} / \mathrm{d} \text {, reaches } \\
\text { the highest level at } 20 \mathrm{~d} \text {, and then stabilizes. This water level is maintained for } 13 \mathrm{~d} \text { and } 8 \mathrm{~h} \text {. Next, the water level } \\
\text { decreases at the rate of } 1 \mathrm{~m} / \mathrm{d} \text { and returns to the initial level at } 20 \mathrm{~d} \text {. }\end{array}$ \\
\hline 2 & $\begin{array}{l}\text { The rate of reservoir water-level fluctuation is } 2 \mathrm{~m} / \mathrm{d} \text { : the reservoir water level rises at the rate of } 2 \mathrm{~m} / \mathrm{d}, \text { reaches the } \\
\text { highest level at } 10 \mathrm{~d} \text {, and then stabilizes. This water level is maintained for } 13 \mathrm{~d} \text { and } 8 \mathrm{~h} \text {. Next, the water level falls at } \\
\text { the rate of } 2 \mathrm{~m} / \mathrm{d} \text { and returns to the initial level at } 10 \mathrm{~d} .\end{array}$ \\
\hline 3 & $\begin{array}{l}\text { The rate of reservoir water-level fluctuation is } 3 \mathrm{~m} / \mathrm{d} \text { : the reservoir water level increase at the rate the } 3 \mathrm{~m} / \mathrm{d} \text {, reaches } \\
\text { the highest level at } 6 \mathrm{~d} \text { and } 16 \mathrm{~h} \text {, and then stabilizes. This water level is maintained for } 13 \mathrm{~d} \text { and } 8 \mathrm{~h} \text {. Next, the water } \\
\text { level decreases at the rate of } 1 \mathrm{~m} / \mathrm{d} \text { and returns to the initial level at } 6 \mathrm{~d} \text { and } 16 \mathrm{~h} .\end{array}$ \\
\hline
\end{tabular}

\section{Result Analysis and Discussion}

\subsection{Variation laws of the saturation line}

When the reservoir water level augments, the reservoir water infiltrates into the side slope. However, a hysteresis effect occurs in the underground water level fluctuation due to seepage resistance. Although the underground water level at the side close to the reservoir has been increased, the water level at the side far from the reservoir is still in a low position (Fig. 4). When the reservoir water level decreases, the underground water level cannot timely respond to reservoir water-level fluctuation due to seepage resistance. Although the underground water level at the side close to the reservoir has been decreased, the water level at the side far from the reservoir is still at a high level (Fig. 5).
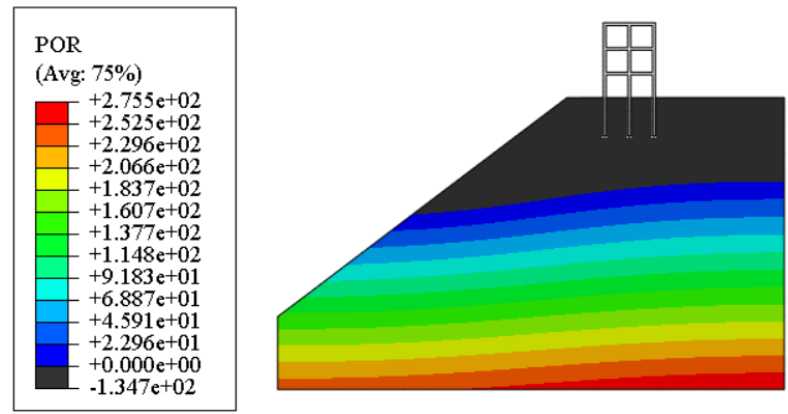

Fig. 4. Saturation line at the increase of the reservoir water level
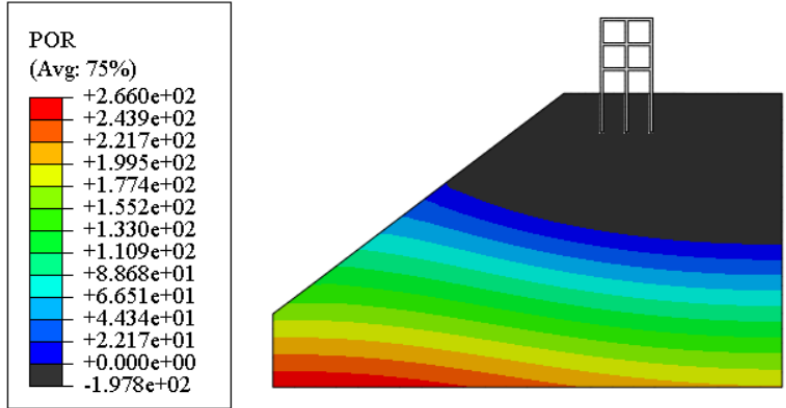

Fig. 5. Saturation line at the decline of the reservoir water level

The variation laws of the saturation lines of the bank slope under three working conditions are shown in Fig. 6 and Fig. 7. The heights of the saturation line at the rear edge of slope when the rate of reservoir water level increase is 1 $\mathrm{m} / \mathrm{d}$ are 1.07 and 1.19 times those when the rates of the reservoir water level increase are 2 and $3 \mathrm{~m} / \mathrm{d}$. This finding indicates that the hysteresis effect of the saturation line is obvious with the increase of the rate of the reservoir water level increase. The height difference of the saturation lines under three working conditions gradually increases when the reservoir water level declines. This phenomenon occurs because the duration of the impacts of seepage resistance on the saturation line is long if the reservoir water-level fall lasts for a prolonged time.

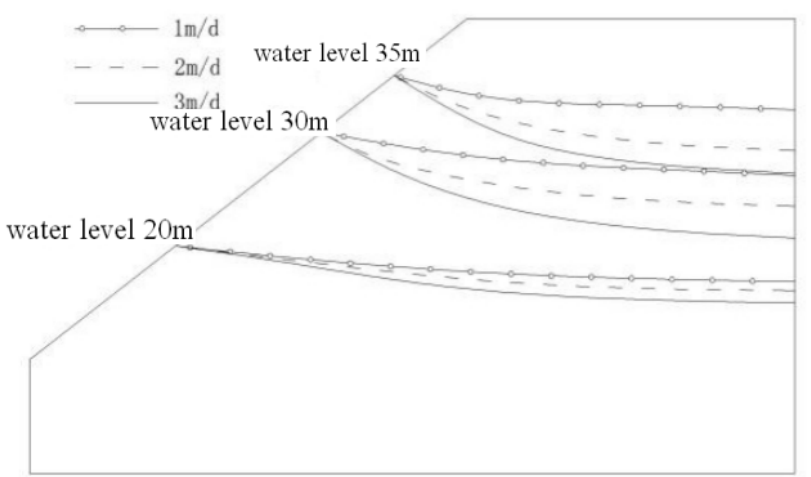

Fig. 6. Variation law of the saturation line at the increase of the reservoir water level

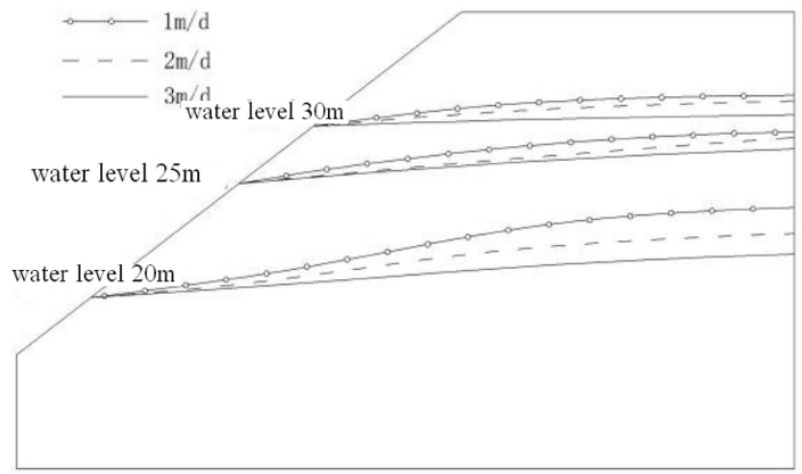

Fig. 7. Variation law of the saturation line at the decline of the reservoir water level

\subsection{Variation law of the soil pore pressure}

The isoline of the initial pore pressure is shown in Fig. 8. The isoline of the pore water pressure at the bank slope when the reservoir water level is increased to the highest level and then stabilizes is shown in Fig. 9. The pore water pressure gradually decreases from the bottom to up and 
reaches zero at the saturation line. In Fig. 8 and Fig. 9, the region from red to green is the positive zone, and that from green to blue is the negative zone.

The influences of reservoir water-level fluctuation on the pore water pressure of the side slope gradually decrease from near to far regions. The difference between the pore pressure in the slope and the water pressure outside the slope increases with the distance from the slope surface. This notion reflects that the hysteresis effect of reservoir waterlevel fluctuation on pore pressure in soil mass is more prominent when it is further away from the reservoir slope surface. Hence, the pore water pressure at the front edge of the slope greatly fluctuates due to the great influence of reservoir water-level fluctuation, while the pore water pressure at the rear edge of the slope slightly changes.

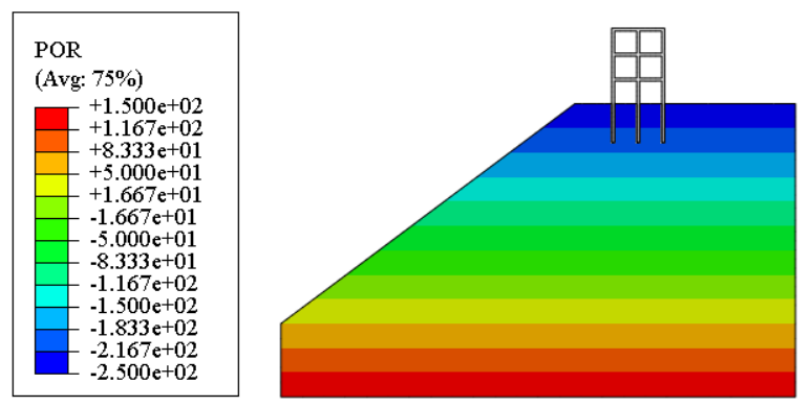

Fig. 8. Isoline of pore pressure before the reservoir water level increase

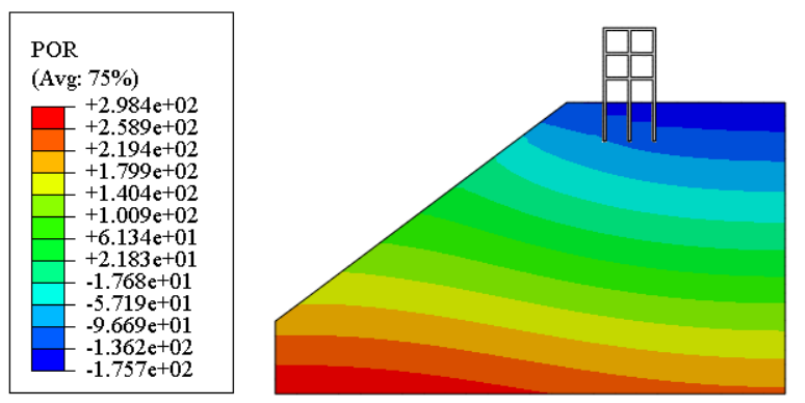

Fig. 9. Isoline of pore pressure at the increase of the reservoir water level

The isolines of pore water pressure on the side slope during and after the decline of the reservoir water level are shown in Fig. 10 and Fig. 11. The comparison result indicates that the slope of the isoline of pore pressure at the upper position of the slope increases to a certain extent after the reservoir water level declines. Meanwhile, the difference of pore pressure at the left and right sides further increases. This situation occurs because the difference between internal and external underground water levels in the slope gradually increases with the continuous drop of the reservoir water level.

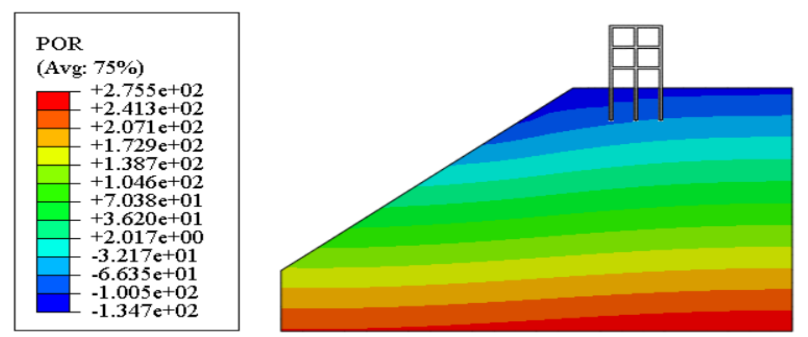

Fig. 10. Isoline of pore pressure at the decline of the reservoir water level
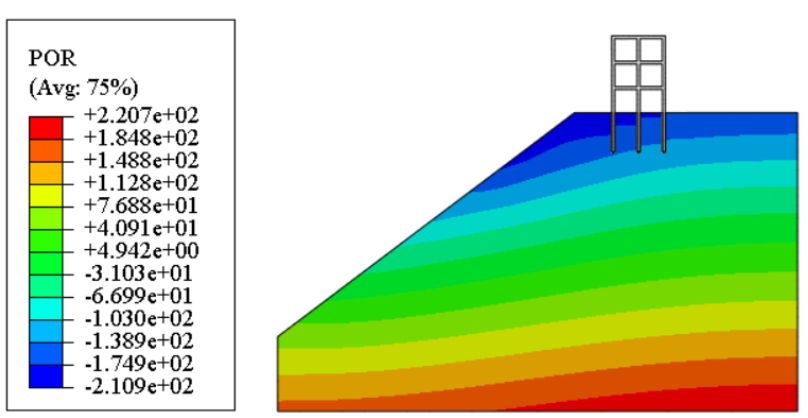

Fig. 11. Isoline of pore pressure after the decline of the reservoir water level

The groundwater level and pore pressure in the slope increase as the storage water level increases, and the matrix suction decreases as the storage water level increases. The resultant force is upward, thus generating heaves of foundation. When the storage water level begins to decrease, the groundwater level and pore pressure in the slope decrease, and the matrix suction increases instead. The resultant force is downward to cause settlement of the building foundations.

\subsection{Effects of reservoir water-level fluctuation on the stress distribution of buildings on the bank slope}

The horizontal stress cloud maps of the side slope at the rise and fall of the reservoir water level are shown in Fig. 12 and Fig. 13, respectively. The stress distribution gradually increases from the slope surface to the internal space of slope when the reservoir water level increases. Such distribution is completely different from the horizontal stress distribution of an ordinary slope. This phenomenon occurs mainly because the soil mass in the slope surface region is hydrated to saturate with the increase of the reservoir water level, while the soil mass in the slope is still unsaturated. The pore water in the soil mass of the slope surface infiltrates into the slope, thereby generating a seepage force.

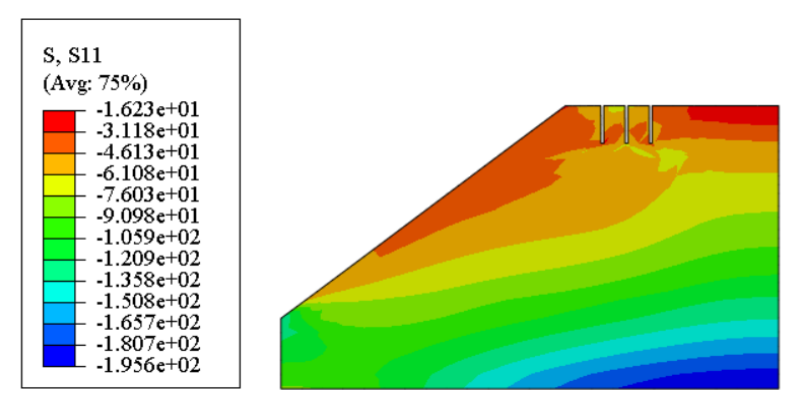

Fig. 12. Horizontal stress at the increase of the reservoir water level

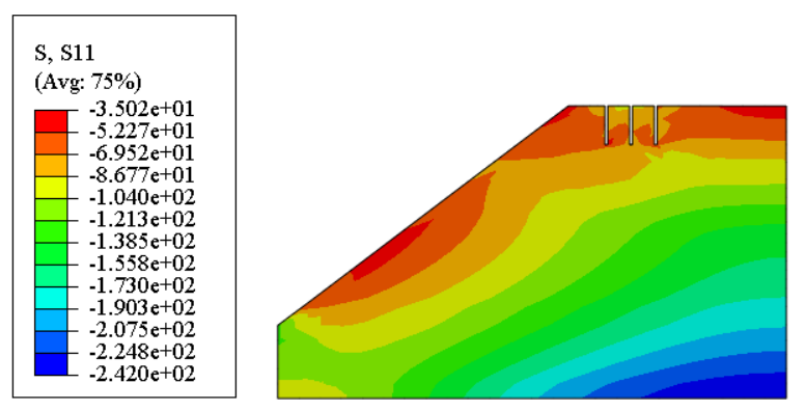

Fig. 13. Horizontal stress at the decrease of the reservoir water level

It can be seen from Figure 14 and Figure 15, the stress distribution state of the side slope slightly changes during the rise and fall of the reservoir water level, as manifested by the changes in the positive, negative, and amplitude 
Wu Liming, Yang Bo, Wang Zijian, Zhang Jianing and Yuan Shifeng/

Journal of Engineering Science and Technology Review 13 (6) (2020) 108 - 117

numerical values. During the increase of the reservoir water level, the stress in the region of the slope surface is positive. This result is obtained mainly because the pore water in the side slope infiltrates upward and generates an upward seepage force. Meanwhile, the side slope is affected by gravity. Accordingly, the vertical stress on slope surface is positive, and the vertical stress in a lower region is negative.

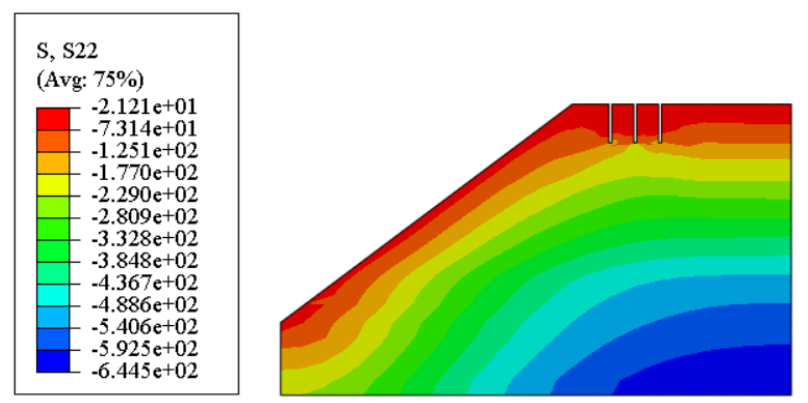

Fig. 14. Vertical stress at the increase of the reservoir water level

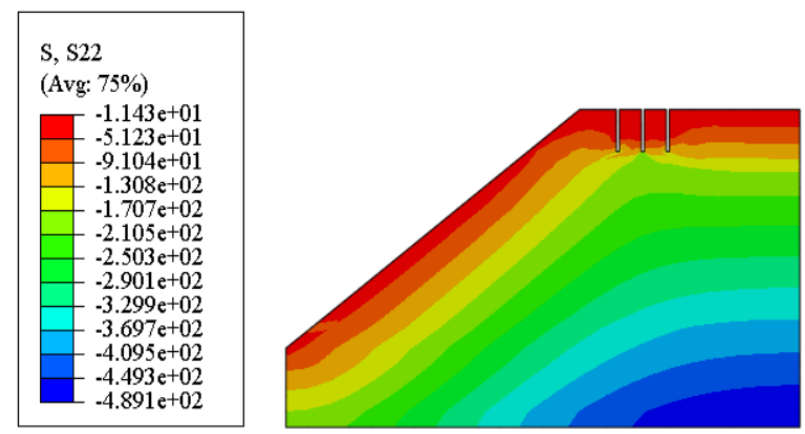

Fig. 15. Vertical stress at the decline of the reservoir water level

The above analysis indicates that the stress state of the building foundation may significantly change during reservoir water-level fluctuation. The vertical stresses at the bottom of the pile foundation of the buildings in the overall model were extracted for curve plotting (Fig. 16). The stress on the left pile foundation (Pile 1\#) is higher than that on the right (Pile 3\#) before the increase of the reservoir water level. With the increase of reservoir water level, the vertical stress on the left pile significantly drops, while that on the right pile decreases at a lower rate. Moreover, the maximum difference of effective stress at the bottom of the pile foundation is $5 \mathrm{kN}$ during reservoir water-level fluctuation. This finding indicates that the reservoir water-level fluctuation can induce great changes in the stress state of the building foundations.

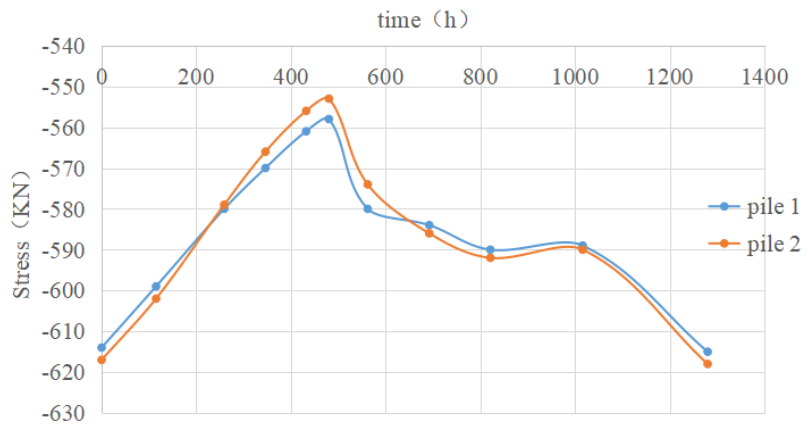

Fig. 16 Variation law of stresses on the bottom of the pile foundation

4.4 Effects of reservoir water-level fluctuation on the deformation of the bank slope and local buildings
4.4.1 Effects of reservoir water-level fluctuation on the deformation of the bank slope

A water head difference between the reservoir and underground water levels is developed due to the hysteresis effect of underground water-level fluctuation when the reservoir water level increases. The underground water infiltrates into the side slope, and an inward seepage force is produced. Meanwhile, the slope surface in the region immersed by reservoir water is also affected by hydrostatic pressure, and the total hydrostatic pressure against the whole slope surface increases with the increase in reservoir water. Effective deformation of the bank slope points into the slope (Fig. 17). When the reservoir water level decreases, it is lower than the underground water level, and an outward seepage force is generated. Moreover, the total hydrostatic pressure against the whole slope surface decreases because the slope surface above the reservoir water level is unaffected by hydrostatic pressure. The side slope is influenced by unloading and effective deformation of the slope body points to the reservoir region (Fig. 18).

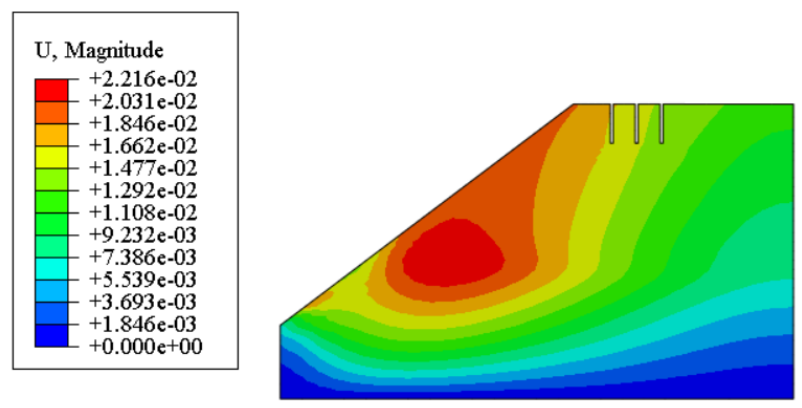

Fig. 17. Deformation at the increase of the reservoir water level

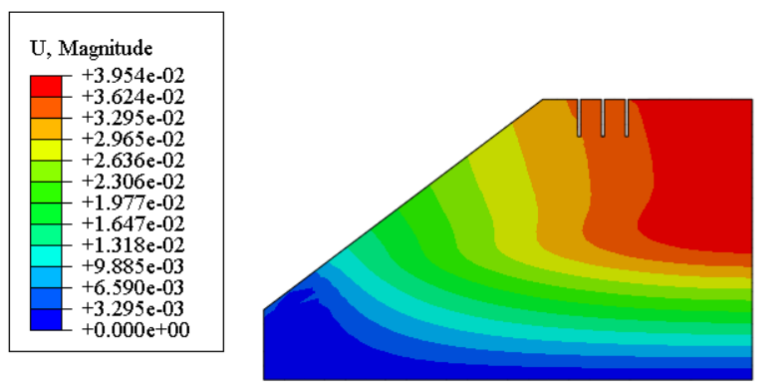

Fig. 18. Deformation at the decline of the reservoir water level

\subsubsection{Influencing laws of reservoir water-level fluctuation} on the settlement of buildings on the blank slope

The settlement laws of building foundations on the bank slope during the reservoir water-level fluctuation have to be analyzed to assure the structural safety of the buildings. The vertical displacement of the most left Pile 1\# (Fig. 19) and vertical displacement at the bottom of the most right Pile $3 \#$ (Fig. 20) were extracted from the overall model for the convenient analysis of the differential settlement.

The above figures demonstrate that the displacement at the bottom of the foundation gradually increases when the reservoir water level augments, and it points upward. This phenomenon occurs because the underground water level increases with the reservoir water level, and the saturated region gradually expands, while the unsaturated region narrows. The negative correlation between matric suction and saturation degree demonstrates that the matric suction of the above slope body decreases. Moreover, the pore water pressure at the lower portion of the slope increases with increase in the underground water level. According to the 
simplified stress relationship of unsaturated soil in ABAQUS (Equation [7]), it can be inferred that when the pore water pressure increases, the effective stress in the soil decreases.

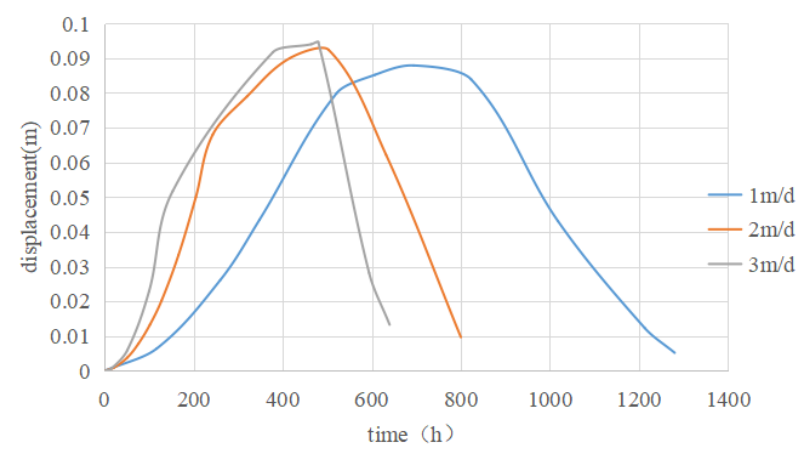

Fig. 19. Vertical displacement of Pile 1\#

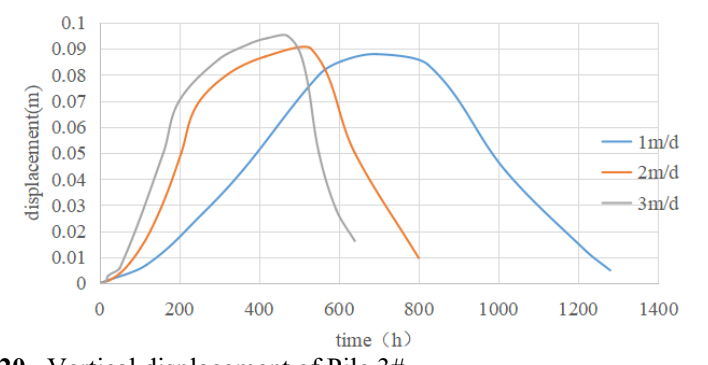

Fig. 20. Vertical displacement of Pile $3 \#$

The matrix suction and effective stress decrease, and the expansion force in the soil increases. When the expansive force exceeds the increased vertical component of the reservoir water pressure, the bank slope develops heaves, and the vertical displacement (upward) of the building foundations increases. The reservoir water is kept constant after reaching the maximum point. Under this circumstance, a difference still exists between the underground and the reservoir water levels. The unsaturated region continues to narrow, while the saturated region remains to expand. The matric suction and effective stress in the slope body continuously decrease. However, the expansive force increases, and the heave in the bottom of foundation presents an upward trend. However, such a growth rate of heave significantly decreases. When reservoir water level declines, the saturated region in the upper slope body narrows, and the unsaturated region is expanded, thus increasing the matric suction and effective stress and decreasing the expansive force. Therefore, the weight of the soil is reduced. The vertical displacement at the bottom of the pile foundation gradually decreases.

$\delta^{\prime}=\delta-\mathrm{S}_{r} \mu_{w}$

The $\sigma^{\prime}$ is the effective stress, $\sigma$ is the net stress, $\mathrm{S}_{\mathrm{r}}$ is the saturation degree, and $\mu \mathrm{w}$ is the pore water pressure.

\subsubsection{Influencing laws of reservoir water-level fluctuation on the horizontal displacement of the building foundations}

Hydrostatic pressure on the slope surface changes throughout the process of reservoir water-level fluctuation. The horizontal component of hydrostatic pressure can affect the horizontal deformation of slope; thus, buildings on the slope generate a horizontal displacement. Moreover, the changes of matric suction and effective stress caused by the underground water level can trigger variations of expansive force of soil mass. Accordingly, the buildings on the slope generate a horizontal displacement. Therefore, the horizontal displacements at the bottom of different piles were extracted and analyzed. The results are shown in Figs. 21, 22, and 23. The maximum displacement of the pile foundation is positively related with the rate of reservoir water-level fluctuation. This notion indicates that the rate of reservoir water-level fluctuation is a key influencing factor in the deformation of buildings on the bank slopes.

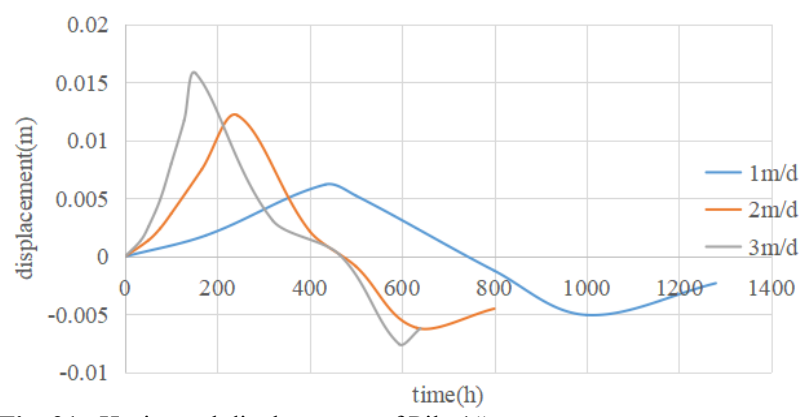

Fig. 21. Horizontal displacement of Pile 1\#

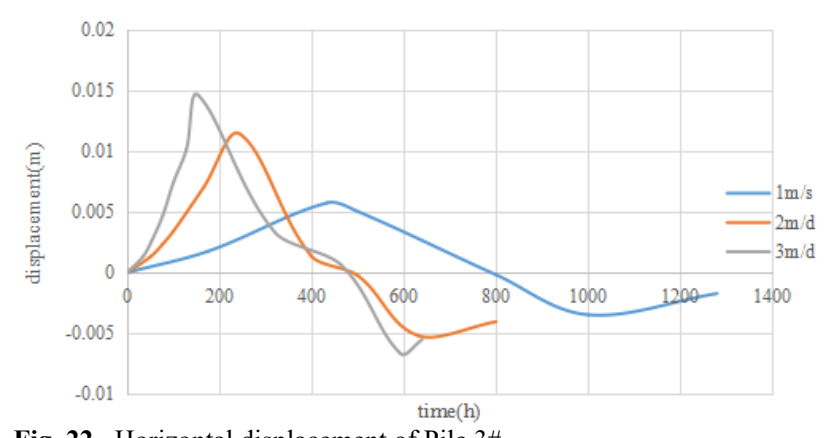

Fig. 22. Horizontal displacement of Pile $3 \#$

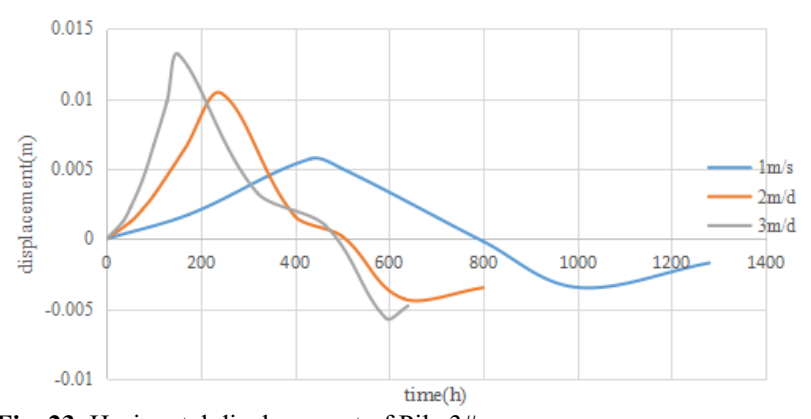

Fig. 23. Horizontal displacement of Pile 3\#

Figs. 21, 22, and 23 demonstrate that when the reservoir water level augments, the horizontal displacement at the bottom of the pile foundation gradually increases. The growth rate of the horizontal displacement and final deformation volume are positively related with the rate of reservoir water-level increase. This finding conforms to the variation law of seepage field. The water level of the reservoir reaches the highest value, and the range where the slope reaches the slope becomes smaller, which leads to the reduction of horizontal seepage force and displacement. When the reservoir water level decreases, the seepage force is an outward one, and the reservoir water pressure decreases, accompanied with the reduction of the slope-oriented deformation of the pile bottom. The outward seepage force is greater than the horizontal component of the reservoir water pressure, and the horizontal displacement of the pile bottom is outward.

The water level of the reservoir decreases, and the maximum horizontal displacement of the pile foundation 
near the reservoir increases. This finding is consistent with deformation laws of the side slope. The horizontal displacement of the building foundations is relatively small, while the vertical displacement is comparatively large. Hence, the reservoir water-level fluctuation can significantly influence the horizontal components of buildings, but it slightly influences the vertical components of buildings on the bank slope.

\subsection{Comparative analysis}

In this study, the settlement of building foundations was calculated according to the layer-wise summation method recommended by the Code for Design of Building Foundation and Code for Design of Building Pile Foundations.

$$
\mathrm{s}=\psi \times \psi_{\mathrm{e}} \times s^{\prime}=4 \times \psi \times \psi_{e} \times p_{0} \sum_{i=1}^{n} \frac{z_{i} a_{i}^{-}-z_{i-1} a_{i-1}^{-}}{E_{s i}}
$$

where $\mathrm{P} 0$ is the additional stress at the bottom of the foundations, and it is calculated as $514.5 \mathrm{kPa} ; \Psi$ is the calculation empirical coefficient of the settlement of the pile foundation; and $\Psi \mathrm{e}$ is the equivalent settlement coefficient of the pile foundation. The settlement calculation depth ( $\mathrm{Zn})$ is determined according to the condition that the additional stress is equal to 0.2 times of the gravity stress of the soil mass. Pile $1 \#$ was chosen for theoretical calculation. The results were compared with the numerical simulation results under Working Condition 1.

During the rising and stable period of the water reservoir water level, the underground water level is relatively low. Without considerations to the influences, the settlement of the pile end is $17.2 \mathrm{~mm}$, and the vertical displacement from the numerical simulation is $15.5 \mathrm{~mm}$ (before geostress balance). When the reservoir is used under the normal pool level, the saturation line of the bank slope increases, and certain parts of the soil quality under the foundation of the building begin to be affected by the groundwater level. Given that the highest reservoir water level is five, which is higher than the bottom surface of the pile foundation, the changes of the elasticity modulus and bulk density of the soil mass caused by water absorption within the calculation depth range below the underground water level shall be simultaneously considered. Hence, the parameters of sand soil 1 were corrected: the elasticity modulus was discounted by $20 \%$ to be $17.6 \mathrm{MPa}$. The bulk density of the soil mass was increased by $3 \%$ to be 12.36 $\mathrm{kN} \cdot \mathrm{m}-3$. The pile-end settlement was calculated to be $19.8 \mathrm{~mm}$. Fig. 21 demonstrates that the numerical simulation result is $5.2 \mathrm{~mm}$.

The layer-wise summation method considers the settlement deformation at the bottom of the pile foundations under actions of the above stresses only, but it ignores the seepage effect. Accordingly, the layer-wise summation method must be further corrected: additional stresses (the difference of stresses at the bottom of the pile foundation before reservoir water-level fluctuation and during the stable operation of the reservoir water level) caused by the seepage effect were extracted and brought into Eq. (8) for calculation. The corrected settlement was determined to be $4.7 \mathrm{~mm}$. Therefore, the numerical simulation error is $9.8 \%$ before reservoir water-level fluctuation, and it is $9.6 \%$ during the stable operation of the reservoir water level.

\section{Conclusions}

This study establishes a 2D overall model of a bank slope in a reservoir region and above buildings by using the finite element software ABAQUS. This initiative is undertaken to disclose the influencing law of reservoir water-level fluctuation on buildings on the bank slope and assure their safety. Based on the saturated-unsaturated seepage basic theory, this study simulates the variations of the seepage field on the bank slope and the displacement and deformation of building foundations. Major conclusions could be drawn:

(1) The stress distribution on the side slope gradually increases from the slope surface to the internal spaces due to reservoir water-level fluctuation.

(2) The rate of reservoir water-level fluctuation is positively related with the displacement rate and maximum displacement of the building foundations. The displacement of the building foundations increases as it approaches the reservoir region. The large difference in the vertical displacements among different pile foundations easily causes shear failure of horizontal structures, such as beam and plates. A small difference in horizontal displacement can be observed among different pile foundations, thus resulting in the small influences of reservoir water-level fluctuation on the vertical structures, such as walls and columns.

(3) When reservoir water level rises, the reservoir water pressure and underground water level in the bank slope increase. The saturated region expands, while the unsaturated region narrows, accompanied with the growth of pore water pressure and decrease of the effective stress in the saturated region and matric suction in the unsaturated region. Accordingly, building foundations develop displacement deformation. The pile foundation generates vertical heaves and horizontal displacement orienting to the bank slope.

(4) When the reservoir water level decreases, the underground water level and reservoir water pressure decline. The saturated region narrows, while the unsaturated region expands. The pore water pressure decreases, and effective stress in the saturated region and the matric suction in the unsaturated region increases accordingly. Finally, the foundations in the bank slope develop shrinkage deformation, and the vertical heave of pile foundation gradually decreases. The horizontal displacement first decreases, then increases toward the opposite direction (changing from pointing to the bank slope to pointing to slope surface), and finally gradually decreases.

(5) he accuracy of the applied saturated - unsaturated fluid - solid coupling analysis is proved through a comparative analysis between the layer-wise summation method and finite element simulation.

The finite element overall model method based on saturated - unsaturated seepage theory can effectively simulate the influences of reservoir water-level fluctuation on buildings on the bank slope. This method can provide references for the design of new buildings and safety evaluation of existing buildings on the bank slope. However, a measurement error may occur during the experiment because the water - soil characteristic curve is difficult to obtain. Therefore, errors in the calculation results are inevitable. In future studies, the experimental method shall be improved to test a highly accurate soil - water characteristic curve, which can make seepage simulation closer to the practical situation. 
Wu Liming, Yang Bo, Wang Zijian, Zhang Jianing and Yuan Shifeng/

Journal of Engineering Science and Technology Review 13 (6) (2020) 108 - 117

\section{Acknowledgements}

The study was supported by Science and Technology

Research Project of Chongqing Education Commission (KJQN201804010; KJQN202004004) and Project of Technological Colleges of Chongqing City (CK2016B09) and Key Scientific Research Projects of Chongqing Technology and Business Institute (NDZD2019-01).

This is an Open Access article distributed under the terms of the Creative Commons Attribution License

\section{References}

1. Zhang, M., "Study on Mechanism of Bank Slope Stability Change under Reservoir Water Level Fluctuation". Master thesis of Chongqing Jiaotong University, China, 2017, pp.1-20.

2. Yang, S., "Zhang Jihuai railway Youshui bridge slope rock mass stability numerical analysis". Railway Construction Technology, 9, 2019, pp.78-81.

3. Liu, X., Fu, H. L., "Stability analysis of high and steep rock slope under reservoir water fluctuation". Science and Technology and Engineering, 17 (24), 2017, pp.263-268.

4. Li, S. X., "Study on the Bearing Capacity of Surrounding Road Subgrade and House Foundation Caused by Reservoir Impoundment". Master thesis of Changsha University of Science and Technology, China, 2016, pp.1-10.

5. Huang, L., "Stability Characteristics of Reservoir Bank Slope and Analysis of Uneven Settlement Cracks of Slope Houses". Master thesis of Central South University, 2012, pp.1-50.

6. Li, Z. C., "Experimental study on bearing capacity of building pile foundation under the influence of reservoir water level fluctuation". Journal of Railway Science and Engineering, 6 (02), 2009, pp.3842.

7. Vipin, K., Vikram, G., Imlirenla, J., "Shovan Lal Chattoraj.Evaluation of potential landslide damming: Case study of Urni landslide,Kinnaur, Satluj valley, India". Geoscience Frontiers, 10(02), 2019, pp.753-767.

8. Shruti, N., "Early warning system for shallow landslides using rainfall threshold and slope stability analysis". Geoscience Frontiers, 9(06),2018, pp.1871-1882.

9. David, J. P., Somerville, Nigel. P., "Impact of a pre - existing transverse drainage system on active rift stratigraphy: An example from the Corinth Rift, Greece". Basin Research, 32(4), 2020, pp.764-788.

10. Joynal, A., Yasin, W. R., Ikramul, H., "An investigation of the characteristics, causes, and consequences of June 13, 2017, landslides in Rangamati District Bangladesh". Geoenvironmental Disasters, 7(1), 2020,pp.1077-1095.

11. Binh, T. P., Indra, P., Jie, D., "A novel hybrid approach of landslide susceptibility modelling using rotation forest ensemble and different base classifiers".Geocarto International, 35(12), 2020, pp.1267-1292.

12. Vito, F., Francesco, G. C., Maria, A., "Establishing a threshold for rainfall - induced landslides by a kinetic energy - duration relationship". Hydrological Processes, 34(16), 2020, pp.3571-3581.

13. Manoj, K. T., Srinivas, D., "Exploring the rainfall data from satellites to monitor rainfall induced landslides A case study". Advances in Space Research, 66(4), 2020, pp.887-894.

14. Raffaele, G., Lucrezia, C., Francesco, P., "Rigid block and finite element analysis of settlement-induced failure mechanisms in historic masonry wall panels". Fracture and Structural Intregrity, 14(51), 2020, pp.517-533.
15. Gianmarco, D. F., Marialaura, M., "Failure pattern prediction in masonry". Journal of Mechanics of Materials and Structures, 14(5) 2019, pp.663-682.

16. Eugeniusz, H., "Effect of settlement of foundations on the failure risk of the bottom of cylindrical steel vertical tanks for liquids". Studia Geotechnica et Mechanica, 41(3), 2019, pp.171-176.

17. Paolo, Z., Nicolò, S., Cyrille, D. T., "Failure analysis of masonry arch with no-horizontal support settlement". Procedia Structural Integrity, 11, 2018, pp.436-443.

18. Jamie, H., Dimitris, T., "Gothic Barrel Vaults under Differential Settlement: The Effects of Boundary Conditions and FRP on Structural Behaviour". Key Engineering Materials, 4516, 2017, pp.496-503.

19. Richard, S., "Settlement of floor slabs on stone columns in very soft clays". Proceedings of the Institution of Civil Engineers Geotechnical Engineering, 170(1), 2017, pp.16-26.

20. Bayer, B., Simoni, A., "Using advanced In SAR techniques to monitor landslide deformations induced by tunneling in the Northern Apennines, Italy". Engineering Geology, 226, 2017, pp.20-32.

21. Casagli, N., Cigna, F., Bianchini, S., "Landslide mapping and monitoring by using radar and optical remote sensing: Examples from the EC-FP7 project SAFER". Remote Sensing Applications: Society and Environment, 4, 2016, pp.92-108.

22. Dalgic, H., "A two-stage numerical analysis approach for the assessment of the settlement response of the pre-damaged historic Hoca Pasha Mosque". International Journal of Architectural Heritage, 13(5), 2019, pp.704-724.

23. Lu, X., Ju, N. P., Deng, T. X., "Influence of transient water level change on reservoir bank slope stability". Science and Technology and Engineering, 18 (25), 2018, pp.236-244.

24. Fang, J. C., Deng, H. F., Xiao, Y., Zhang, H. B., Wang, C., "Sensitivity analysis of influencing factors on bank slope stability under combined action of reservoir water and rainfall". Water Conservancy and Hydropower Technology, 48 (03), 2017, pp.146152.

25. Guo, J. X., Graeber, P. W., "Landslide forecasting based on hydrological process simulation for a dump slope in an open mining pit”. Journal of Groundwater Science and Engineering, 6(02), 2018, pp.92-103.

26. Liu, W. Y., Zhang, L. H., Chen, J. H., Duan, X., "Influence of reservoir water level change on reservoir bank subgrade settlement". Hydrogeology and Engineering geology, 43(03), 2016, pp.141-147.

27. Cho, S. E., Lee, S. R., "Instability of unsaturated soil slopes due to infiltration". Computers and Geotechnics, 28(3), 2001, pp.185-208. 